\title{
SISTEM INFORMASI SIMPAN PINJAM BADAN USAHA MILIK DESA (BUMDES) SUMBER MULYA KABUPATEN LAMANDAU BERBASIS WEBSITE
}

\author{
Abertun Sagit Sahay ${ }^{\mathrm{a}, 1^{*}}$, Felicia Sylviana ${ }^{\mathrm{b}, 2}$, Wiwit Trianto ${ }^{\mathrm{c}, 3}$ \\ ${ }^{a}$ Jurusan Teknik Informatika FT UPR, Jl H. Timang Tunjung Nyaho \\ b Jurusan Teknik Informatika FT UPR, J1 H. Timang Tunjung Nyaho \\ 'Jurusan Teknik Informatika FT UPR, Jl H. Timang Tunjung Nyaho \\ abertun@gmail.com ${ }^{1}$; felicia.upr@gmail.com2; tiwiworiantt@ gmail.com ${ }^{3}$ \\ * corresponding author
}

ARTICLE INFO

Keywords

Information system

Save and loan

web

bumdes

\section{ABSTRACT}

Bumdes is a village business institution managed by the community and village government in an effort to strengthen the village economy and is formed based on the needs and potential of the village. Some activities in this business entity are still not computerized, such as in savings and loan transactions, this is still done manually, so it requires quite a long time in the process. then made a website-based information system. The method used in doing the design is to use the waterfall model, Stages in the waterfall: Definition of Needs, System and Software Design, Implementation and Testing of Units, Implementation and Testing, Integration and Testing. Data analysis techniques used are field studies and literature studies. This program was created using the PHP language and using the MySql database. Based on the above problems, it is necessary to make a computer-based Information System with the title Savings and Loans Information System of Village-Owned Enterprises (Bumdes) Sumber Mulya Kab. Lamandau Based on Website. Helps present a more organized data management and more efficient report management.

\section{Pendahuluan}

\subsection{Latar Belakang}

Sistem informasi (SI) adalah kombinasi dari teknologi informasi dan aktivitas orang yang menggunakan teknologi itu untuk mendukung operasi dan manajemen. Sistem informasi merupakan fokus utama dari studi untuk disiplin sistem informasi dan organisasi informatika. Dan oleh karena itu sistem informasi yang berbasis komputasi sudah banyak diterapkan oleh setiap organisasi, contohnya usaha simpan pinjam seperti koperasi.

Koperasi adalah organisasi bisnis yang dimiliki dan dioperasikan oleh orang-seorang demi kepentingan bersama. Dalam pengerjaannya koperasi juga memerlukan sebuah sistem informasi untuk mempermudah dalam melakukan pekerjaannya.

Disini penulis mengambil contoh salah satu badan usaha simpan pinjam yaitu Bumdes Sumber Mulya Yang berada di kec. Sematu Jaya, Kab. Lamandau, Tujuan dari pendirian Bumdes yaitu untuk Mensejahterakan Masyarakat desa purwareja. Bumdes sumber mulya sendiriberdiri pada 28 November 2015 dan mulai aktif pada 1 maret 2016. Proses pengerjaan pada badan usaha ini belum semuanya terkomputerisasi, seperti dalam transaksi simpan pinjam, segala pencatatan kegiatan simpan pinjam ini masih dikerjakan secara manual, membuat laporan yang masih dikerjakan secara manual sehingga membutuhkan waktu yang cukup lama belum lagi harus merekap semua data-data kegiatan yang dilakukan sehingga dapat menghambat pembuatan laporan dan untuk pengerjaan. 


\section{JURNAL TEKNOLOGI INFORMASI}

[E-ISSN 2656-0321]

[Vol 13. No. 1]

Jurnal Keilmuan dan Aplikasi Bidang Teknik Iniommatika

[Januari 2019]

Dari permasalahan diatas, maka perlu dibuat sebuah aplikasi/SI yang berbasis komputer dengan judul "Sistem Informasi Simpan Pinjam Bumdes Sumber Mulya Kab. Lamandau Berbasis Website".

Adapun Maksud dan Tujuan Dari Penelitian ini adalah :

1. Membantu Bumdes dalam mengelola transaksi simpan pinjam yang terjadi dengan menggunakan sistem yang terkomputerisasi.

2. Membantu pengelolaan anggota yang bergabung dengan Bumdes secara terkomputerisasi.

3. Membantu dalam pencarian data anggota yang memiliki peminjaman.

4. Membantu dalam pengelolaan laporan simpan pinjam penyewaan kios, retribusi buah sawit dan pengtelolaan pengeluaran dana.

1.2. Manfaat Penelitian

Hasil penelitian ini adalah memberikan sebuah aplikasi Bumdes Sumber Mulya :

1. Membantu seluruh anggotanya dalam melakukan pengelolaan transaksi simpan pinjam.

2. Membantu dalam pengelolaan data yang lebih teratur sehingga lebih membantu dalam kegiatan transaksi.

\section{Metodologi Penelitian}

1. Metode pengumpulan data

Metode yang di gunakan penulis dalam mengumpulkan data adalah :

a. Studi Lapangan yaitu dengan melakukan observasi dalam penelitian langsung ke objek yang di teliti.

b. Studi Kepustakaan yaitu dengan membaca dan mempelajari buku-buku yang berhubungan dengan perancangan sistem informasi Bumdes Sumber Mulya serta Refensi dari internet.

2. Metode Pengembangan Perangkat Lunak

Fase-fase dalam Waterfall Model menurut referensi Sommerville :

a. Requirements definition

b. System and software design

c. Implementation and unit testing

d. Integration and system testing

e. Operation and maintenance

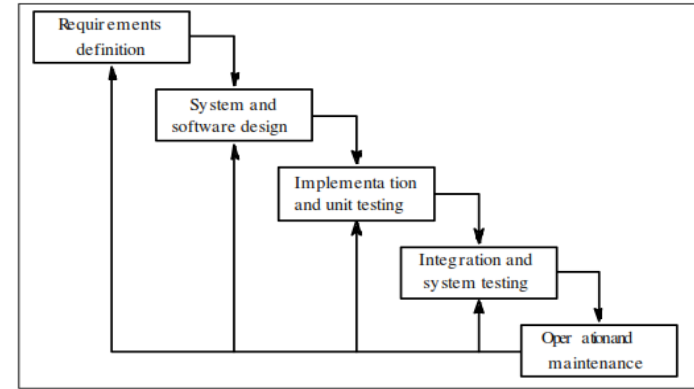

Gambar 1. Diagram Alur Waterfall Model (Sommerville, 2011)

\section{Hasil dan Pembahasan}

3.1. Analisa Kebutuhan

1. Analisa pengguna

a. Administrator, merupakan user (pengguna) yang memilki hak akses penuh dan menyeluruh terhadap sistem/website. 


\section{JURNAL TEKNOLOGI INFORMASI}

[E-ISSN 2656-0321]

[Vol 13. No. 1]

b. anggota adalah pengguna yang dapat mengakses halaman anggota yang memiliki akses yang terbatas terhadap sistem.

2. Analisa Informasi

Analisa terhadap informasi apa saja yang ada di dalam website yaitu :

a. Anggota yang bergabung dalam Bumdes.

b. Informasi transaksi simpan pinjam yang dilakukan dalam Bumdes.

c. Informasi Penyewaan bangunan/kios pasar berjualan.

d. Informasi Retribusi Buah sawit yaitu penyaluran buah sawit dari masyarakat ke pabrik sawit

\subsection{Data Design}

1. Diagram Konteks (DFD Level 0)

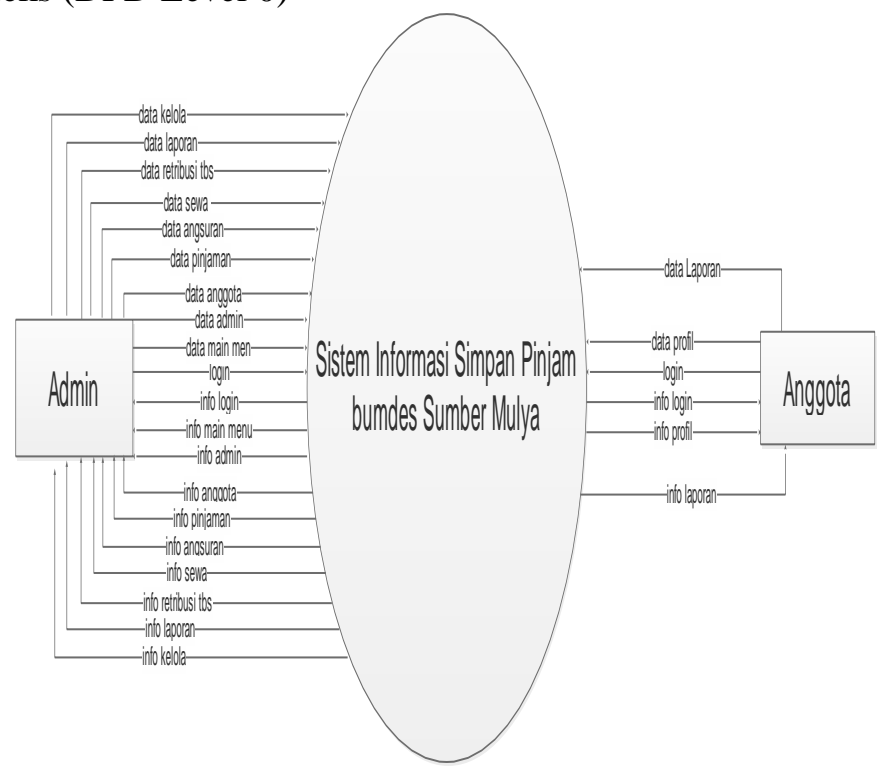

Gambar 2. Diagram konteks (Level 0)

2. Entity Relationship Diagram

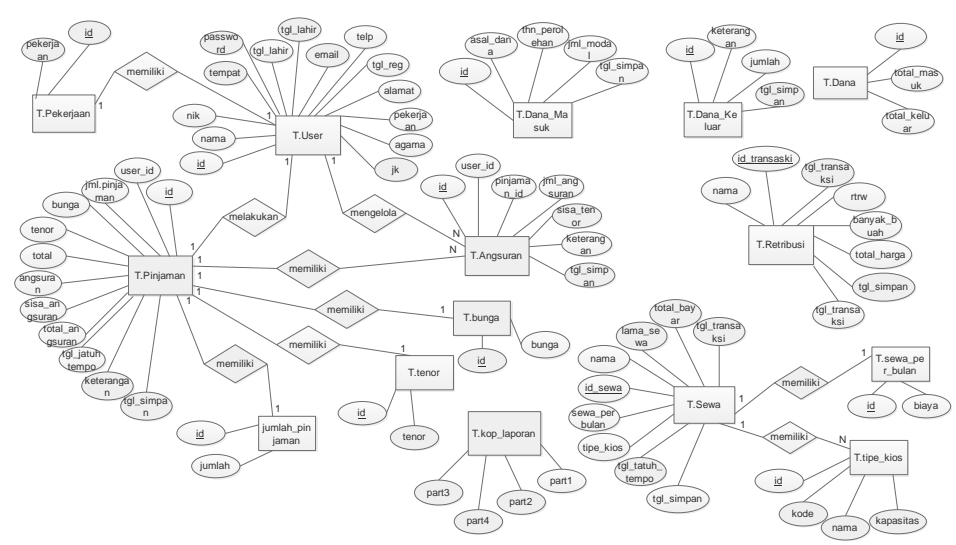

Gambar 3. ERD Sistem Informasi Simpan Pinjam Bumdes

\subsection{Antarmuka Sistem}

1. Halaman Menu Utama 


\section{JURNAL TEKNOLOGI INFORMASI}

[E-ISSN 2656-0321]

[Vol 13. No. 1]

Jurnal Keilmuan dan Aplikasi Bidang Teknik Iniommatika

[Januari 2019]

Halaman ini berisi informasi sumber dana pemasukan dan pengeluaran yang terjadi di bumdes, padahalaman ini juga terdapat informasi jumlah kios yang tersedia dan kios yang sedang disewa, untuk lebih jelasnya dapat dilihat pada screenshoot berikut.

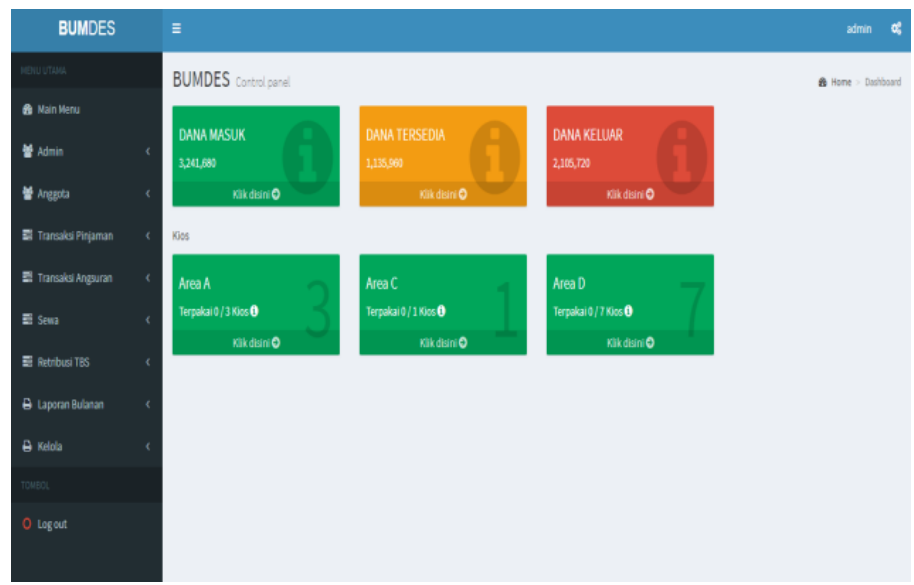

Gambar 4. Implementasi Halaman Menu Utama

2. Halaman Data Anggota

Halaman ini merupakan halaman dimana terdapat data profil dari anggota yang ada. Disini admin juga dapat melakukan ubah data anggota dan menghapus anggota yang sudah tidak aktif, berikut merupakan screenshot dari halaman data anggota.

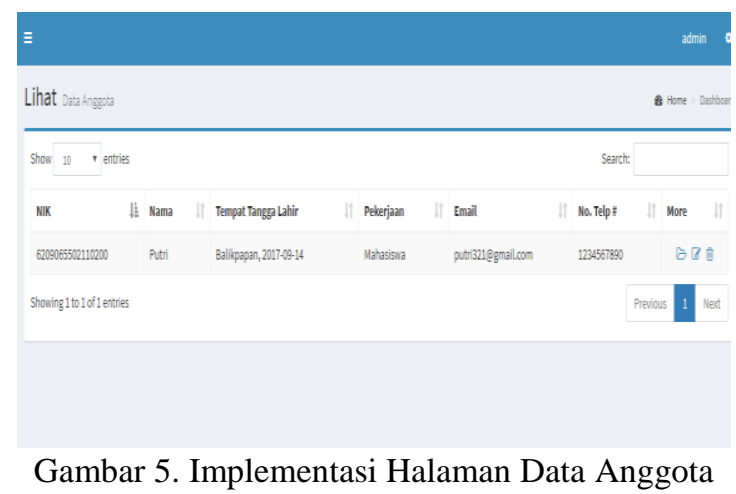

3. Halaman Data Peminjaman

Halaman ini merupakan dimana admin melakukan proses transaksi peminjman yang dilakukan oleh anggota, disini tercatat semua piminjaman yang dilakukan anggota. Berikut ini merupakan screenshoot dari halaman peminjaman.

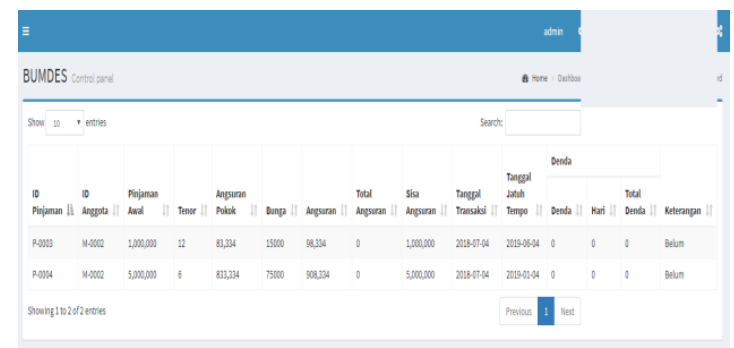

Gambar 6. implementasi Halaman Data Pinjaman 


\section{JURNAL TEKNOLOGI INFORMASI}

[E-ISSN 2656-0321]

[Vol 13. No. 1]

Jurnal Keilmuan dan Aplikasi Bidang Teknik Iniormatilka

4. Halaman Data Angsuran

Halaman ini merupakan halaman dimana semua histori angsuran peminjam tercatat, berikut ini merupakan screenshoot dari halaman angsuran.

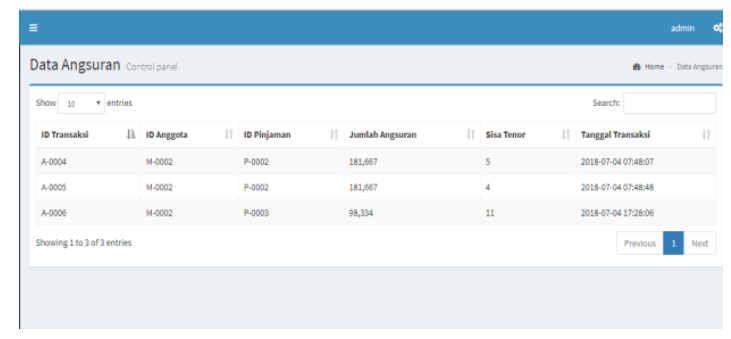

Gambar 7. Implementasi Halaman Data Angsuran

5. Halaman Data Sewa

Halaman ini merupakan daftar semua penyewa kios pasar yang ada di bumdes, untuk lebih jelasnya dapat di llihat pada screenshoot pada gambar di bawah ini.

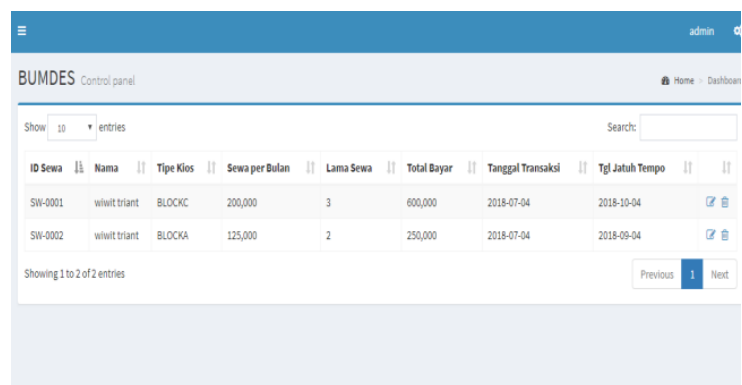

Gambar 8. Implementasi Halaman Data Sewa

6. Halaman Data Retribusi TBS

Halaman ini merupakan daftar seluruh tengkulak yang telah melakukan transaksi dengan bumdes yang ada di bumdes, untuk lebih jelasnya dapat di llihat pada screenshoot pada gambar di bawah ini.

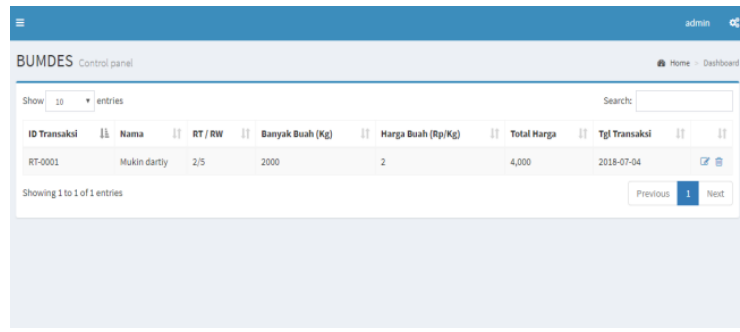

Gambar 9. Implementasi Halaman Distribusi

7. Halaman Laporan Pinjaman

Laporan pinjaman merupakan histori peminjaman anggota yang sedang melakukan peminjaman, disini admin juga dapat melakukan cetak data laporan berdasarkan bulan yang di inginkanm untuk lebih jelasnya dapat dilihat pada screenshoot di bawah ini. 


\section{JURNAL TEKNOLOGI INFORMASI}

[E-ISSN 2656-0321]

[Vol 13. No. 1]

Jurnal Keilmuan dan Aplikasi Bidang Teknik Iniommatika

[Januari 2019]

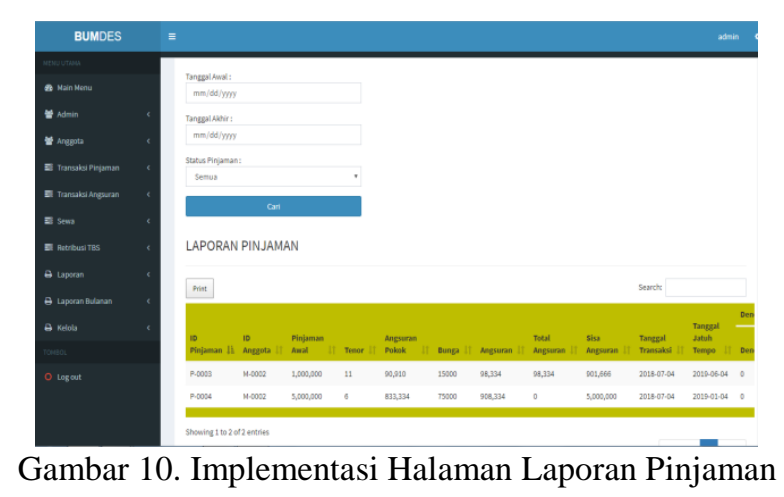

8. Halaman Pengaturan

Halaman kelola ini merupakan fitur yang berfungsi untuk mengubah nilai-nilai dalam sistem bumdes agar bersifat fleksibel seperti jumlah peminjaman yang dapat dilakukan anggota, bunga perbulan, tenor (waktu angsuran) peminjaman dan data kios.

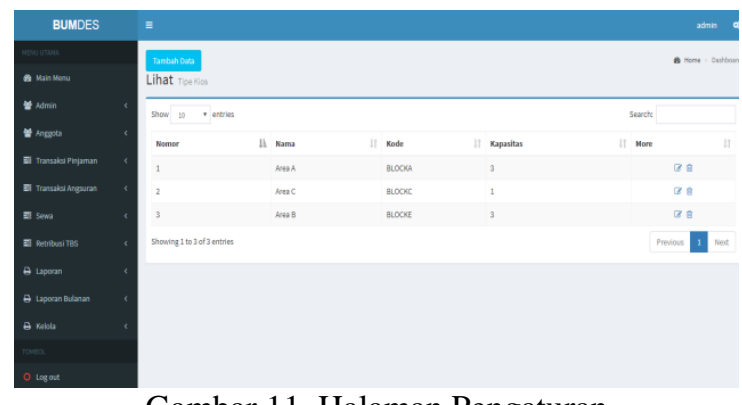

Gambar 11. Halaman Pengaturan

9. Halaman Profil Anggota

Halaman ini merupakan halaman yang berisi profil/data diri dari anggota, anggota juga dapat melakukan edit data profil jika ada perubahan data. Berikut implementasi halaman profil anggota.

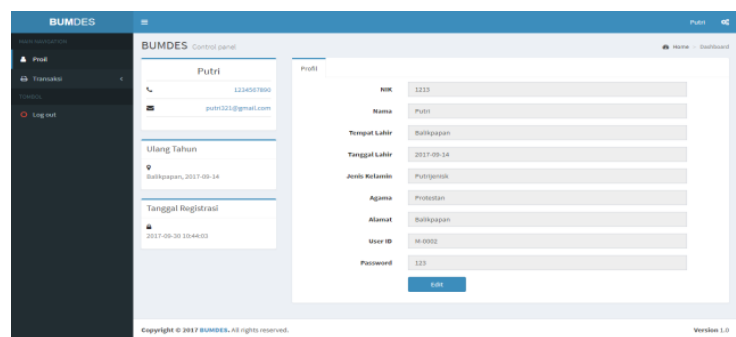

Gambar 12. Implentasi Halaman Profil Anggota

10. Halaman Laporan Transaksi Pinjaman (Anggota)

Halaman transaski pinjaman merupakan halaman dimana data peminjmanan anggota tersimpan, disini anggota dapat melihat informasi tentang peminjaman yang dilakukan. Berikut merupakan implementasi halaman transaksi laporan peminjaman. 


\section{JURNAL TEKNOLOGI INFORMASI}

[E-ISSN 2656-0321]

[Vol 13. No. 1]

\section{Jurnal Keilmuan dan Aplikasi Bidang Teknik Iniormatika}

[Januari 2019]

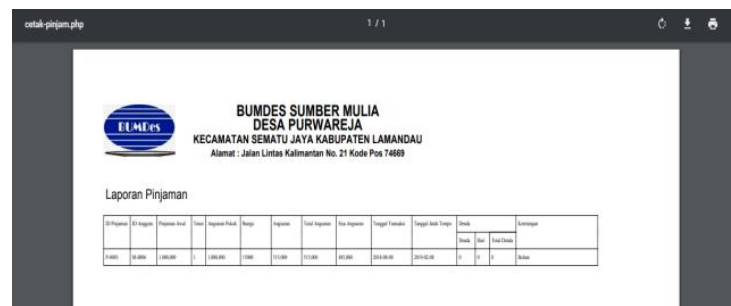

Gambar 13. Cetak Laporan Pinjaman

\section{KESIMPULAN}

\subsection{Kesimpulan}

Proses perancangan sistem informasi simpan pinjam badan usaha milik desa (bumdes) metode yang digunakan yaitu metode waterfall, tahapan metode waterfall adalah Requirements definition(Definisi Kebutuhan), System and software design(Desain Sistem dan Perangkat Lunak), Implementation and unit testing (Implementasi dan Pengujian Unit), Integration and system testing (Pengintregrasian dan Pengujian Sistem) dan Operation and maintenance(Pengoperasian dan Pemeliharaan). Metode yang digunakan untuk perancangan sistem yaitu DFD (Data Flow Diagram), serta untuk melakukan pengujian sistem menggunakan metode Black Box.

Berikut ini merupakan fitur-fitur yang disediakan :

1) Registrasi Anggotamerupakan fitur dimana calon peminjam dapat melakukan pendaftaran diri untuk menjadi anggota,

2) Profil Anggota merupakan fitur untuk anggota yang telah terdaftar.

3) Anggotamerupakan daftar semua anggota dan staff yang bertugas menjalankan Bumdes Sumber Mulya

4) Transaksi Simpan Peminjamanmerupakan fitur untuk melakukan trasaksi peminjaman.

5) Retribusi TBS (Tandan Buah Segar) merupakan fitur untuk melakukan kegiatan transaksi buah sawit.

6) Sewa Kiosmerupakan fitur untuk kegiatan penyewaan kios pasar.

7) Laporan merupakan fitur yang menyediakan laporan kegiatan bumdes.

Berdasarkan pengujian seluruh fitur menggunakan black box testing dapat di simpulkan tidak terdapat error pada fitur yang telah dibuat, seluruh fitur dapat berjalan sesuai dengan yang di harapkan dan tidak terjadi error

\subsection{Saran}

Berdasarkan kesimpulan yang telah di ambil, diharapkan peneliti dapat mengembangkan lagi dan menambah fitur dari sistem informasi simpan pinjam ini seperti pengelolaan SHU dan sistem ini dapat di kembangkan lagi secara online.

\section{DAFTAR PUSTAKA}

[1] Betha Sidik. 2017 “Pemrograman WEB dengan PHP 7'Penerbit Iformatika

[2] Gregorius. (2000,30). Pengertian Web. Dikutip 9 Desember 2018 dari web ku: http://https://web-kuweb.blogspot.com/2017/08/pengertian-website.html.

[3] Heni Sri Wahyuni .2009"Sistem informasi simpan pinjamdi dinas koperasi ukm dan perindagkota bandung”. Bandung 


\section{JURNAL TEKNOLOGI INFORMASI}

[E-ISSN 2656-0321]

[Vol 13. No. 1]

Jurnal Keilmuan dan Aplikasi Bidang Teknik Iniormatilka

[Januari 2019]

[4] Hidayatullah. Priyanto. (2017). Apa itu MySQL. Dikutip 22 April 2017 dari worldpress: http://zoyi.wordpress.com/2010/10/30/apa-itu-mysqlapache-dan-php/.

[5] Hidayatullah. Priyanto, 2017 "Pemrograman Web”, Bandung, Informatika Bandung.

[6] Jogiyanto, H.M. 2005. Analisis dan Desain Sistem Informasi (Pendekatan Terstruktur Teori dan Praktek Aplikasi Bisnis),AndiOffset, Yogyakarta.

[7] Muhammad Arif Zulfikar .2012"Sistem informasi simpan pinjam pada koperasi “kopka”temanggung”. Temanggung.

[8] Mukhamad Masrur, 2016 "Pemrograman Web Dinamis Menggunakan Java Server Pages Dengan Database Relational MySQL”, Yogyakarta, Andi.

[9] Nugroho (2004,2). Pengertian HTML. Dikutip 9 Desember 2018 dari repository: http://http://repository.polimdo.ac.id/42/1/Gabriela\%20Krisia\%20Mentari\%20Liotohe.pdf.

[10] Nugroho. Bunafit (2008, 29). Pengertian MySQ. Dikutip 9 Desember 2018 dari elib unikom: http://https://elib.unikom.ac.id/files/disk1/446/jbptunikompp-gdl-davidivanc-22264-9-babiil-i.pdf.

[11] Prihatna, H. 2005, “Kiat Praktis Menjadi Web Master Profesional”. Elex Media Komputindo.

[12] Raharjo,Budi. 2011. Belajar Otodidak Membuat Database Menggunakan MySQL. Bandung: Informatika

[13] Ramdhani (2003). Pengertian Internet. Dikutip 9 Desember 2018 dari dosenit: http:// https://dosenit.com/jaringan-komputer/internet/pengertian-internet-menurut-ahli.

[14] Sidharta (1996). Pengertian Internet. Dikutip 9 Desember 2018 dari dosenit: http:// https://dosenit.com/jaringan-komputer/internet/pengertian-internet-menurut-ahli.

[15] Sibero (2011) .Pengertian Internet. Dikutip 9 Desember 2018 dari dosenit: http:// https://dosenit.com/jaringan-komputer/internet/pengertian-internet-menurut-ahli

[16] Syafii. M. (2004, 1). Pengertian PHP. Dikutip 22 April 2017 dari academia edu: http:// http://www.academia.edu/4603746/Pengertian_PHP_My

[17] Stendy B. Sakur. (2010). PHP 5 Pemograman Berorientasi Objek.Yogyakarta:Penerbit Andi.

[18] Sutanta, E., (2004). Sistem Basis data. Yogyakarta: Penerbit Graha Ilmu.

[19] S, Rosa A. dan M. Shalahuddin. (2014). Rekayasa Perangkat Lunak Terstruktur dan Berorientasi Objek.Bandung:Informatika Bandung.

[20] Widiarty, W. (2017). Rancang Bangun Website Sistem Informasi Praktikum Jurusan Teknik Informatika Univeritas Palangka Raya. Jurnal SAINTEKOM, 6(2), 12-24. 